\title{
Avaliação da qualidade físico-química e microbiológica do leite cru, do leite pasteurizado tipo A e de pontos de contaminação de uma Granja Leiteira no RS
}

\author{
Evaluation of physical, chemical and microbiological quality of raw and pasteurized grade A milk \\ and points of contamination at a dairy farm in RS
}

\section{Vanessa Aparecida de Mello da Silva', Paula Marques Rivas', Maira Balbinotti Zanela², Andrea Troller Pinto $^{2}$, Maria Edi Rocha Ribeiro ${ }^{3}$, Fabiana Fernanda Pacheco da Silva' \& Maluza Machado'}

\begin{abstract}
RESUMO
O leite tipo A, produzido e beneficiado em granja leiteira, possui padrões de qualidade específicos. O objetivo desse trabalho foi avaliar a qualidade físico-química e microbiológica do leite cru e pasteurizado tipo A e de pontos de contaminação em uma granja leiteira do RS. De novembro de 2006 a abril de 2008 foram realizadas seis coletas. A cada coleta foram amostrados: leite cru e pasteurizado, swabes de tetos e teteiras para contagem de coliformes totais, termotolerantes, bactérias mesófilas aeróbias e psicrotróficas. Foi realizada análise físico-química do leite. A contagem de coliformes totais e termotolerantes no leite pasteurizado indicou que 50\% e 33,3\% das amostras estavam fora do padrão, respectivamente. Na contagem de mesófilos aeróbios no leite pasteurizado, duas amostras apresentaram resultados acima do limite estabelecido pela Instrução Normativa 51 (IN51). No leite cru, 3 amostras apresentaram elevadas contagens de mesófilos aeróbios ( $\left.>1,0 \times 10^{4} \mathrm{UFC} / \mathrm{mL}\right)$. A quantidade de psicrotróficos do leite cru variou entre as coletas. Houve aumento dos valores entre a primeira e a última coleta para as contagens na superfície das teteiras do início para o fim do período da ordenha. $\mathrm{Na}$ análise físico-química do leite foi verificado que duas amostras de leite cru e uma amostra de leite pasteurizado apresentaram teores de gordura abaixo do mínimo permitido (3,0\%). A contagem de células somáticas apresentou valores acima do permitido para 3 amostras de leite cru e 1 amostra de leite pasteurizado. Verificou-se a necessidade de correções no manejo de ordenha, a fim de melhorar a qualidade do leite produzido e se adequar às normas da IN51.
\end{abstract}

Descritores: coliformes termotolerantes, coliformes totais, contagem de aeróbios, qualidade do leite.

ABSTRACT

Grade A milk is produced and processed by rigid and specific standard of quality. This research aimed to evaluate microbiological, physical and chemical characteristics of raw and pasteurized grade A milk and know some critical points of contamination at a dairy farm in Rio Grande do Sul. For November, 2006 to April, 2008 we carried out six visits and sample collection at the property. At each one, there were collected samples of raw and pasteurized milk, swabs of teats skin and milking machine liners. There were performed aerobic mesophiles counting and total and fecal coliforms (MPN). To raw milk, it was also performed psychrotropic counting. About total and fecal coliforms counting, 50 and $33.3 \%$ of the pasteurized milk samples were above the legal standard (IN 51). About aerobic mesophilic bacteria counting, 2 samples were considered inappropriate. Raw milk presented high aerobic mesophiles counting $\left(>1.0 \times 10^{4} \mathrm{CFU} / \mathrm{mL}\right.$ in 3 samples). At liners, we observed that counts increase between the first and the last sampling. The first raw milk and fifth pasteurized milk presented low fat percent $(<3.0 \%)$. Somatic cells counts were higher than legal standard at five raw and one pasteurized milk samples. It is necessary to improve milk quality by correct milk and cow management to adequate production to the legal standards.

Keywords: fecal coliforms, total coliforms aerobic count, milk quality. 


\section{INTRODUÇÃO}

O leite pasteurizado tipo A, segundo IN51 [2], é o leite beneficiado e envasado na granja leiteira. Em comparação com os diferentes tipos de leite, o leite tipo A apresenta os padrões de qualidade mais rígidos quanto às características microbiológicas e contagem de células somáticas e requisitos especiais quanto à sua produção e industrialização.

A qualidade microbiológica do leite pode ser comprometida devido às condições de higiene durante a ordenha, de limpeza de utensílios e equipamentos antes e após a pasteurização, do processo tecnológico e até mesmo as condições climáticas da região, dentre outros fatores $[4,6]$. A higienização dos tetos antes da ordenha contribui para melhorar a qualidade do leite e prevenir e controlar as infecções da glândula mamária [8].

As células somáticas do leite são constituídas de leucócitos e células epiteliais, encontrando-se em elevado número em caso de mastite. A contagem de células somáticas (CCS) é um instrumento preciso de avaliação da saúde da glândula mamária dos animais, tanto individualmente como de um rebanho. Altas contagens de células somáticas resultam em perdas na produção e alterações nos componentes individuais do leite, com comprometimento sobre o rendimento e a qualidade de seus derivados [11].

O objetivo desse trabalho foi avaliar a qualidade físico-química e microbiológica do leite cru e do leite pasteurizado tipo A produzido no RS, comparando com a legislação vigente, além de analisar as possíveis contaminações de tetos e teteiras durante o período de ordenha.

\section{MATERIAIS E MÉTODOS}

O presente estudo foi realizado em uma granja leiteira no leste do RS. A propriedade possuía cerca de 89 vacas em lactação, da raça Holandês. A sala de ordenha era do tipo espinha de peixe, duplo 4, com sistema de ordenha canalizado. A ordenha era realizada 2 vezes por dia, com intervalo de 12 horas. A alimentação concentrada era fornecida antes da ordenha. O manejo da ordenha compreendia: prédipping, teste da caneca para identificação de mastite clínica, ordenha e pós-dipping. O pré-dipping era feito com o uso de uma toalha umedecida com detergente alcalino. Não era realizada a secagem da pele dos tetos.
De novembro de 2006 a abril de 2008 foram realizadas seis visitas à propriedade. Em cada visita, foram coletados: uma amostra de $500 \mathrm{~mL}$ de leite cru do tanque de resfriamento, em frasco estéril, uma amostra de leite pasteurizado (embalagem original) e swabes de tetos e teteiras (após higienização e antes da ordenha), no período inicial e final da ordenha, totalizando seis swabes por coleta. Os swabes foram acondicionados em tubos estéreis contendo $10 \mathrm{~mL}$ solução salina $0,85 \%$.

As amostras foram transportadas até o Laboratório de Inspeção e Tecnologia de Leite e Derivados, Ovos e Mel (LEITECIA) da Faculdade de Veterinária da Universidade Federal do Rio Grande do Sul (UFRGS), acondicionados em caixas de isopor com gelo reciclável.

As amostras de leite cru e de leite pasteurizado foram analisadas quanto à composição química, caracterização física, contagem de células somáticas e análises microbiológicas.

A caracterização física foi realizada no LEITECIA, sendo realizados os testes de acidez titulável, densidade, teste do álcool 80\% e fervura. Uma alíquota das amostras foi encaminhada para o Laboratório de Qualidade do Leite da Embrapa Clima Temperado para determinação dos teores de gordura, proteína bruta, lactose e sólidos totais por radiação infravermelha e contagem de células somáticas por citometria de fluxo. Os teores de sólidos desengordurados foram obtidos por subtração da gordura nos sólidos totais.

As análises microbiológicas realizadas no leite cru foram: contagem de coliformes totais, termotolerantes, mesófilos aeróbios e psicrotróficos. A análise de psicrotróficos não foi realizada no leite pasteurizado. Bactérias do grupo das mesófilas aeróbias foram quantificadas mediante plaqueamento em Ágar Padrão para Contagem (PCA), incubando-se a $35^{\circ} \mathrm{C} / 48$ horas. A contagem de psicrotróficos do leite cru foi realizada através da técnica de semeadura em profundidade, empregando-se Ágar Padrão para contagem com incubação a $7^{\circ} \mathrm{C}$ durante 10 dias. A análise de coliformes totais e termotolerantes foi realizada pelo método do Número Mais Provável, utilizando-se Caldo Bile Verde Brilhante e EC e incubando-os, respectivamente a $35^{\circ} \mathrm{C} / 48$ horas e $42^{\circ} \mathrm{C} / 48$ horas [3].

Nos swabes de tetos e teteiras foram realizados: contagem de coliformes totais e coliformes ter- 
mo-tolerantes e contagem de mesófilos aeróbios, utilizando a mesma metodologia, considerando a primeira diluição como sendo $10^{\circ}$.

Os resultados das análises microbiológicas foram apresentados por coleta e foram calculadas as médias para os componentes do leite, CCS e densidade.

\section{RESULTADOS}

A Tabela 1 apresenta os resultados médios de coliformes totais $(\mathrm{Ct})$, coliformes termotolerantes (CT), contagem de mesófilos aeróbios (ME) e psicrotróficos (PS) das amostras de leite cru e de leite pasteurizado tipo A da granja leiteira estudada. Segundo a IN51, o leite cru tipo A pode ter no máximo $1,0 \times 10^{4} \mathrm{UFC} / \mathrm{mL}$, sendo que 3 amostras apresentaram valores acima do limite máximo permitido. A quantificação de microrganismos psicrotróficos apresentou grande variabilidade entre as coletas. O leite pasteurizado tipo A, segundo a legislação, deve apresentar coliformes totais $<0,3 \mathrm{NMP} / \mathrm{mL}$, ausência de coliformes termotolerantes e contagem padrão máxima de $1,0 \times 10^{3} \mathrm{UFC} / \mathrm{mL}$ [2]. A contagem de coliformes totais e termotolerantes no leite pasteurizado indicou que $50 \%$ e $33,3 \%$ das amostras estavam fora do padrão, respectivamente. Na contagem de mesófilos aeróbios no leite pasteurizado, duas amostras apresentaram resultados acima do limite estabelecido pela IN51.

A Tabela 2 apresenta as contagens de Ct, CT e ME nos tetos e teteiras no início e fim da ordenha. Observa-se nas teteiras o aumento da carga bacteriana ao longo do período de ordenha.

A média dos resultados dos componentes do leite, da CCS e da densidade estão apresentados na Tabela 3. As porcentagens de gordura, proteína bruta e sólidos desengordurados do leite cru refrigerado e do leite pasteurizado tipo A tiveram valores médios dentro dos limites mínimos propostos pela IN51, que são respectivamente: $3,0 \% ; 2,9 \%$ e $8,4 \%$. Entretanto, em três amostras, os teores de gordura ficaram leve-

Tabela 1. Coliformes totais $(\mathrm{Ct})$, coliformes termotolerantes $(\mathrm{CT})$, contagem de mesófilos aeróbios (ME) e psicrotróficos (PS) no leite cru e no leite pasteurizado tipo A.

\begin{tabular}{|c|c|c|c|c|c|}
\hline \multirow[t]{2}{*}{ Amostra } & \multirow[t]{2}{*}{ Coletas } & \multicolumn{4}{|c|}{ Análise } \\
\hline & & $\begin{array}{c}\mathrm{Ct} \\
\mathrm{NMP} / \mathrm{mL}\end{array}$ & $\begin{array}{c}\text { CT } \\
\text { NMP/mL }\end{array}$ & $\begin{array}{c}\text { ME } \\
\text { UFC/mL }\end{array}$ & $\begin{array}{c}\text { PS } \\
\text { UFC/mL }\end{array}$ \\
\hline \multirow{6}{*}{ Leite Cru } & 1 & 9,3 & $<0,3$ & $2,35 \times 10^{4}$ & $5,5 \times 10^{3}$ \\
\hline & 2 & 15 & 4,3 & $8,75 \times 10^{3}$ & $2,5 \times 10^{4}$ \\
\hline & 3 & 21 & 7,5 & $2,53 \times 10^{4}$ & $4,0 \times 10^{2}$ \\
\hline & 4 & $\geq 110$ & 24 & $1,9 \times 10^{4}$ & $9,1 \times 10^{3}$ \\
\hline & 5 & $\geq 110$ & 15 & $6,8 \times 10^{3}$ & NR \\
\hline & 6 & $\geq 110$ & $\geq 110$ & $3,4 \times 10^{2}$ & $5,4 \times 10^{1}$ \\
\hline \multirow{6}{*}{$\begin{array}{c}\text { Leite } \\
\text { Pasteurizado }\end{array}$} & 1 & $<0,3$ & $<0,3$ & NR & NR \\
\hline & 2 & $<0,3$ & $<0,3$ & NR & NR \\
\hline & 3 & 3,9 & 3,9 & NR & NR \\
\hline & 4 & 21 & $<0,3$ & $2,7 \times 10^{2}$ & NR \\
\hline & 5 & $\geq 110$ & 2,3 & $2,3 \times 10^{3}$ & NR \\
\hline & 6 & $<0,3$ & $<0,3$ & $>1,0 \times 10^{5}$ & NR \\
\hline
\end{tabular}

*NR - não realizado 
mente abaixo do mínimo permitidos (2,89, 2,97 e 2,99\%), sendo duas em leite cru e uma em leite pasteurizado.

A CCS do leite cru ficou acima do limite máximo permitido para o leite tipo A, que é de
$6,0 \times 10^{5}$ cél $/ \mathrm{mL}$. Três amostras apresentaram valores elevados, que foram: 6,$6 ; 7,2$ e $8,6 \times 10^{5}$ cél $/ \mathrm{mL}$. No leite pasteurizado tipo A, apenas a primeira amostra apresentou valores de CCS elevados $\left(7,2 \times 10^{5}\right.$ cél $\left./ \mathrm{mL}\right)$.

Tabela 2. Coliformes totais (Ct), coliformes termotolerantes (CT) e contagem de mesófilos aeróbios (ME) em tetos e teteiras, coletados no início e fim do período de ordenha.

\begin{tabular}{|c|c|c|c|c|}
\hline \multirow[t]{2}{*}{ Amostra } & \multirow[t]{2}{*}{ Coletas } & \multicolumn{3}{|c|}{ Análise } \\
\hline & & $\begin{array}{c}\text { Ct } \\
\text { NMP/unidade }\end{array}$ & $\begin{array}{c}\text { CT } \\
\text { NMP/unidade }\end{array}$ & $\begin{array}{c}\text { ME } \\
\text { UFC/unidade }\end{array}$ \\
\hline \multirow{6}{*}{ Teto início } & 1 & $<0,3$ & $<0,3$ & $1,0 \times 10^{3}$ \\
\hline & 2 & $<0,3$ & $<0,3$ & $1,0 \times 10^{2}$ \\
\hline & 3 & 0,4 & $<0,3$ & $1,4 \times 10^{4}$ \\
\hline & 4 & 3,5 & 0,4 & $6,3 \times 10^{3}$ \\
\hline & 5 & 1,5 & 0,3 & $2,1 \times 10^{2}$ \\
\hline & 6 & 2,3 & 2,3 & $>1,0 \times 10^{5}$ \\
\hline \multirow{6}{*}{ Teto fim } & 1 & 0,4 & $<0,3$ & $2,1 \times 10^{4}$ \\
\hline & 2 & 0,4 & $<0,3$ & $7,0 \times 10^{2}$ \\
\hline & 3 & $<0,3$ & $<0,3$ & $3,2 \times 10^{3}$ \\
\hline & 4 & 1,5 & $<0,3$ & $5,1 \times 10^{1}$ \\
\hline & 5 & 12 & $<0,3$ & $1,8 \times 10^{2}$ \\
\hline & 6 & 0,3 & 0,3 & $1,8 \times 10^{2}$ \\
\hline \multirow{6}{*}{ Teteira início } & 1 & $<0,3$ & $<0,3$ & $4,0 \times 10^{3}$ \\
\hline & 2 & $<0,3$ & $<0,3$ & $2,0 \times 10^{2}$ \\
\hline & 3 & $<0,3$ & $<0,3$ & $5,5 \times 10^{1}$ \\
\hline & 4 & 1,1 & $<0,3$ & $1,0 \times 10^{1}$ \\
\hline & 5 & 7,5 & 2,3 & $2,1 \times 10^{2}$ \\
\hline & 6 & $<0,3$ & $<0,3$ & $9,3 \times 10^{1}$ \\
\hline \multirow{6}{*}{ Teteira fim } & 1 & $<0,3$ & $<0,3$ & $1,5 \times 10^{3}$ \\
\hline & 2 & 46 & 0,4 & $6,6 \times 10^{3}$ \\
\hline & 3 & 4,3 & 4,3 & $5,0 \times 10^{3}$ \\
\hline & 4 & 21 & 4,3 & $2,6 \times 10^{2}$ \\
\hline & 5 & 15 & $<0,3$ & $2,5 \times 10^{2}$ \\
\hline & 6 & 2,3 & 2,3 & $>1,0 \times 10^{5}$ \\
\hline
\end{tabular}


Todas as amostras de leite cru e de leite pasteurizado apresentaram resultado negativo ao teste do álcool $80 \%$ e a fervura.

\section{DISCUSSÃO}

A carga bacteriana do leite pode ser um indicativo da qualidade sanitária do rebanho e das condições higiênicas na produção do leite [1]. A IN51 determina que para o leite cru refrigerado tipo A, a contagem padrão em placas (CPP) de mesófilos aeróbios seja de no máximo $1,0 \times 10^{4} \mathrm{UFC} / \mathrm{mL}$ e de células somáticas no máximo $6,0 \times 10^{5} \mathrm{cé} / \mathrm{mL}$. Com relação ao leite pasteurizado, este deve apresentar após o processo de pasteurização, contagem de coliformes totais menor que $0,3 \mathrm{NMP} / \mathrm{mL}$, ausência de coliformes termotolerantes e CPP de mesófilos aeróbios de até $1,0 \times 10^{3} \mathrm{UFC} / \mathrm{mL}$. Estes resultados podem indicar problemas no processamento do leite que podem ser devidos a falhas no binômio tempo $\mathrm{x}$ temperatura da pasteurização ou contaminação posterior ao tratamento térmico, como por exemplo na embalagem do leite ou problemas de manutenção do pasteurizador.

As altas contagens de mesófilos aeróbios no leite cru demonstram uma provável contaminação da matéria-prima durante a sua obtenção. Esse fato indica falhas dos procedimentos higiênico-sanitários na obtenção do leite, podendo ser citada a inadequação do manejo pré-ordenha, como a limpeza e desinfecção insuficiente dos tetos. Contagens inferiores de mesófilos aeróbios no leite cru foram encontradas em Londrina-PR (1,9 x $\left.10^{3} \mathrm{UFC} / \mathrm{mL}\right)$ [10].
As contagens de mesófilos aeróbios do leite pasteurizado foram elevadas em duas amostras, sendo que, em uma delas, a contagem foi maior que $1,0 \times 10^{4} \mathrm{UFC} / \mathrm{mL}$. A contaminação inicial alta pode trazer como consequência a sobrevivência de um elevado número de microrganismos após o tratamento térmico. Alguns autores encontraram valores elevados para mesófilos aeróbios (7,4 x 103 UFC/mL) [10]. Em São Paulo, cerca de 44,4\% de amostras de leite pasteurizado tipo A apresentavam valores acima do permitido pela legislação para contagem de mesófilos aeróbios [7]. Outros autores avaliaram 28 amostras de leite pasteurizado tipo A, e encontraram $10,7 \%$ amostras com contagens de mesófilos aeróbios acima do limite [5].

No leite pasteurizado, os valores médios de coliformes totais de 3 amostras foram maiores que o máximo permitido pela legislação. A presença de coliformes termotolerantes foi verificada em duas amostras. Pesquisas realizadas na cidade de São Paulo revelaram que, de 9 amostras de leite pasteurizado tipo A analisadas, 66,7\% e 55,6\% das amostras apresentavam-se fora do padrão para coliformes totais e termotolerantes, respectivamente [7]. As altas contagens verificadas para coliformes totais, termotolerantes e mesófilos aeróbios no leite pasteurizado podem indicar uma recontaminação após o processo térmico, ou a sobrevivência em caso de falhas no mesmo.

Embora tenha havido uma grande variabilidade nos achados referentes a contagem de bactérias psicotróficas no leite cru, os resultados são preocu-

Tabela 3. Teores médios de gordura, proteína bruta, lactose, sólidos totais, sólidos desengordurados, contagem de células somáticas (CCS) e densidade do leite cru Tipo A e leite pasteurizado tipo A.

\begin{tabular}{ccc}
\hline Análises & Leite Cru tipo A & Leite Pasteurizado tipo A \\
\hline Gordura (\%) & 3,31 & 3,38 \\
Proteína Bruta (\%) & 3,33 & 3,30 \\
Lactose (\%) & 4,45 & 4,41 \\
Sólidos Totais (\%) & 11,97 & 12,02 \\
Sólidos Desengordurados (\%) & 8,66 & 8,64 \\
CCs (x 105cél/mL) & 6,84 & 5,03 \\
Densidade (g/L) & 1031,4 & 1031,2 \\
\hline
\end{tabular}


pantes, uma vez que este grupo de microrganismos predomina em situações de deficiência de higiene de ordenha, bem como de limpeza e sanitização de equipamentos, quando associados ao resfriamento inadequado do leite [11]. Superfície de tetos e equipamento de ordenha são considerados as principais fontes de contaminação do leite por esse grupo de bactérias. Embora a maioria desses microrganismos seja destruída durante a pasteurização, a atividade enzimática lipolítica e proteolítica permanece, provocando alterações posteriores nos produtos derivados.

A superfície dos tetos dos animais apresentaram baixas contaminações. No entanto, as contagens médias das teteiras apresentaram aumentos de coliformes totais, termotolerantes e mesófilos aeróbios entre o início e o fim da ordenha. Esse fato sugere que o manejo de limpeza e desinfecção dos tetos e teteiras é inadequado, pois permite o aumento da contaminação das teteiras, as quais não são limpas durante o período entre o início e o final da ordenha. Em trabalho realizado nos Estados Unidos foram encontrados valores maiores que o presente estudo para mesófilos aeróbios em tetos higienizados, variando entre $3,1 \times 10^{4}$ UFC/teto e $1,4 \times 10^{5}$ UFC/teto [1]. Assim sendo, os resultados deste experimento indicam que, de uma maneira geral, os tetos das vacas estudadas apresentaram boa higienização.

Com relação às análises físico-químicas do leite cru e pasteurizado, os valores de gordura encontrados em algumas coletas podem ser considerados baixos, se compararmos o teor médio de gordura citado para a raça holandês de 3,64\% [9]. Vários fatores podem resultar em diminuição da gordura do leite, entre eles, relação entre o volumoso e o concentrado na dieta, baixos teores de fibra efetiva no alimento, estresse térmico, mudanças bruscas na dieta, ou pela diluição dos componentes quando em elevadas produções [9]. Entretanto, não se dispõe de informações a respeito do manejo nutricional desses animais que possibilitem maiores inferências. Devese considerar, também, a possibilidade de falhas na homogeneização do leite, no momento da coleta de leite na propriedade.

As altas contagens de células somáticas no leite cru são fortes indícios de inflamação intramamária. Para uma glândula sadia, são considerados normais valores de CCS abaixo de 200.000 células $/ \mathrm{mL}$ [11]. Foi observada uma CCS acima do limite permitido também na primeira coleta do leite pasteurizado. Esse valor se deve à alta contagem inicial do leite cru.

\section{CONCLUSÕES}

Algumas amostras de leite cru e leite pasteurizado tipo A apresentaram, em diferentes coletas, resultados incompatíveis com os limites definidos pela legislação vigente. Além disso, nos pontos de contaminação analisados (tetos e teteiras) houve a ocorrência de contagens de coliformes totais, termotolerantes e mesófilos aeróbios elevados, indicando deficiência de manejo durante a ordenha. Este fato refletiu também na saúde da glândula mamária, resultando em contagens de células somáticas elevadas no leite. Verificou-se a necessidade de correções no manejo de ordenha, a fim de melhorar a qualidade do leite produzido e se adequar às normas da IN51.

\section{REFERÊNCIAS}

1 Bramley A.J. \& McKinnon C.H. 1990. The microbiology of raw milk. In: Robinson R.K. (Ed). Dairy Microbiology: The Microbiology of Milk. 2nd edn. London: Elsevier Science, pp.163-207.

2 Brasil. Ministério da Agricultura, Pecuária e Abastecimento. 2002. Departamento de Inspeção de Produtos de Origem Animal. Instrução Normativa nº51 de 18 de setembro de 2002. Aprova e oficializa o Regulamento técnico de identidade e qualidade de leite pasteurizado tipo A. Disponível em: <http://www.agricultura.gov.br>. Acessado em 07/2009.

3 Brasil. Ministério da Agricultura, Pecuária e Abastecimento. 2003. Secretaria de Defesa Agropecuária. Instrução Normativa $\mathrm{N}^{\mathrm{o}}$ 62, de 26 de agosto de 2003. Oficializa os Métodos Analíticos Oficiais para Análises Microbiológicas para Controle de Produtos de Origem Animal e Água. Disponível em: <http://www.agricultura.gov.br> Acessado em 07/2009.

4 Froeder E., Pinheiro A.J.R. \& Brandão S.C.C. 1985. Variação da qualidade microbiológica de leite cru tipo "C" da Região de Viçosa. Revista do Instituto de Laticínios Cândido Tostes. 40 (241): 55-68.

5 Nader Filho A., Amaral L.A. \& Rossi Jr. O.D. 1997. Características microbiológicas do leite pasteurizado tipo "Integral", processado por algumas mini e macro-usinas de beneficiamento do Estado de São Paulo. Higiene Alimentar 11 (50): 21-23.

6 Oliveira J.S. 1976. Qualidade microbiológica do leite. Revista do Instituto de Laticínios Cândido Tostes. 31 (186): 15-20. 
7 Oliveira R.P.S. 2005. Condições microbiológicas e avaliação da pasteurização e amostras de leite comercializadas no município de Piracicaba-SP. 81f. Piracicaba, SP. Dissertação (Mestrado) - Escola Superior de Agricultura Luiz de Queiroz ESALQ, Universidade de São Paulo.

8 Pankey J.W. 1989. Hygiene at milking time in the prevention of bovine mastitis. British Veterinary Journal. 145: 401-409.

9 Peres J.R. 2001. O leite como ferramenta do monitoramento nutricional. In: González F.D., Dürr J.W. \& Fontaneli R.S. (Eds). Uso do leite para monitorar a nutrição e o metabolismo de vacas leiteiras. Porto Alegre: UFRGS, pp.5-21.

10 Santana E.H.W., Beloti V., Barros M.A.F., Moraes L.B., Gusmão V.V. \& Pereira M.S. 2001. Contaminação do leite em diferentes pontos do processo de produção: I. Microrganismos aeróbios mesófilos e psicrotróficos. Semina Ci Agrárias. 22 (2): 145-154.

11 Santos M.V. \& Fonseca L.F.L. 2007. Estratégias para controle de mastite e melhoria da qualidade do leite. São Paulo: Manole, 314p. 